\title{
A stratigraphy of Nature Geoscience
}

\author{
We look back on which geologic intervals have most often informed the science published in the journal.
}

T ime is central to the geosciences. Many research questions depend on figuring out when and how the Earth system has changed. Relevant processes, however, can operate on time scales well beyond instrumental records. Constraints on past environmental conditions from the geologic record, based on proxies ranging from ocean sediments to ice cores to tree rings, can help fill this gap. Not all of the about 4.5 billion years of Earth history gets the same amount of attention. We examined our archive to determine which geologic time intervals most frequently featured in Nature Geoscience.

Remarkably, the distribution of articles through geologic time has been fairly consistent since our launch (Fig. 1). The Cenozoic era - the past 65 million years - received the lion's share of attention, having been the focus of $60-80 \%$ of palaeoclimate articles.

Within the Cenozoic, the recent Holocene and Pleistocene epochs are extremely well-represented, likely the result of abundant study material spread across the globe. Further back in time, the Eocene epoch - from 56 to 35 million years ago - also stands out. Often investigated as a possible analogue of future greenhouse warming, studies of episodes of extreme global temperatures during the Eocene have helped shed light on factors responsible hot past climates. Widespread cooling associated with a major expansion of the Antarctic Ice Sheet during the following Oligocene epoch - from 35 to 23 million years ago - has received comparatively less attention.

A substantial number of studies also examined intervals associated with major mass extinctions. Some helped better understand the global environmental and biotic response to the CretaceousPalaeogene mass extinction, which occurred 66 million years ago and marked the demise of the dinosaurs. Further back in time, others touched on a vigorous debate regarding the cause of a mass extinction spanning the Permian/Triassic boundary around 242 million years ago, which saw

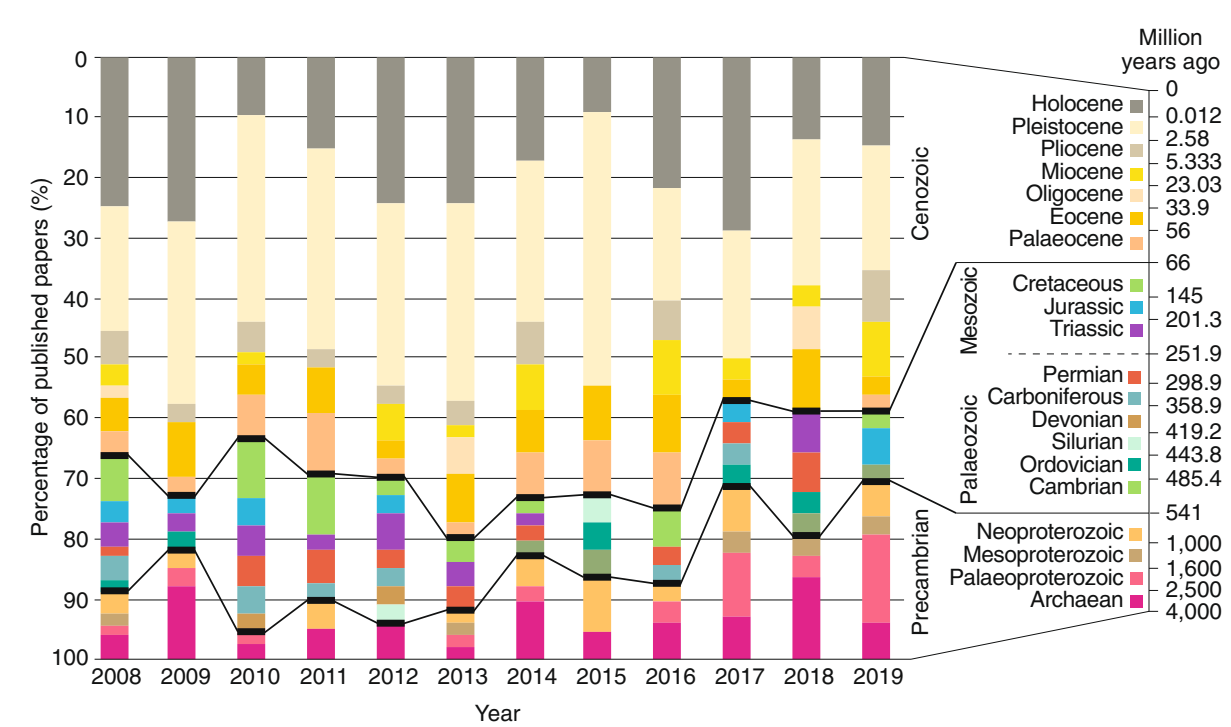

Fig. 1 | Geologic time intervals representative of palaeoclimate articles published in Nature Geoscience since 2008. Data are shown as a percentage of the total number of relevant papers, which ranged between 40 and 50 each year. Articles were counted in particular time intervals if they were the focus of the primary conclusions of a paper. When conclusions spanned multiple intervals, each interval was counted separately. This resulted in some double-counting of Pleistocene and Holocene articles, for instance, though the general patterns hold regardless.

the disappearance of more than $90 \%$ of existing species.

The Devonian and the Silurian periods from 443 to 359 million years ago - are notably the focus of the fewest studies in Nature Geoscience. This is somewhat surprising, considering that they are associated with the rise of terrestrial plants.

The proportion of studies centred on the $\sim 90 \%$ of Earth history represented by the Precambrian grew from about $10 \%$ in the early years of the journal to about $20-30 \%$ now. Coaxing information out of a fragmented sedimentary record, this work contributed to a developing understanding of the development of Earth's atmosphere and the emergence of life. Recent technical advances may have opened new avenues to investigate Earth's oldest history.

The number of articles we have published for each time interval is not entirely determined by geologic time or the availability of material to analyse. Clearly, the scientific community also play an important role in setting which time intervals get the spotlight, bearing in mind the patterns reported here are only representative of one journal.

Indeed, we are aware that sets of articles in an influential journal can change perspectives on the importance of particular topics and times. The distribution of articles through geologic time in Nature Geoscience therefore represents a complicated feedback between the interests of researchers, editors and funders.

From our vantage point, we encourage geoscientists to explore the whole of Earth history. Fundamental insights often spring from unexpected intervals or archives.

Published online: 6 January 2020 https://doi.org/10.1038/s41561-019-0525-1 